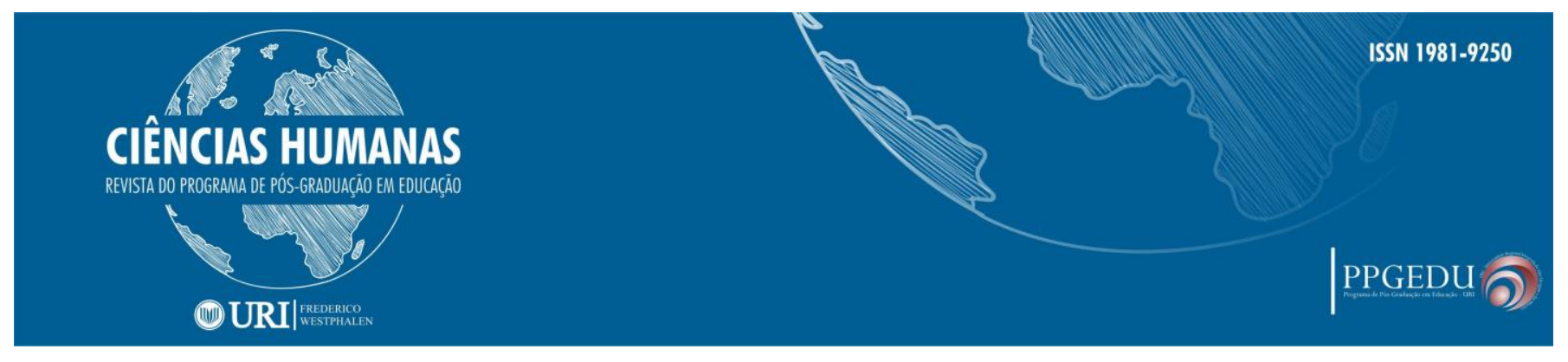

\title{
ÉTICA, DERECHOS, VALORES Y ESCÁNDALOS ÉTICOS
}

\author{
ÉTICA, DIREITOS, VALORES E ESCÂNDALOS ÉTICOS \\ ETHICS, RIGHTS, VALUES AND ETHICAL SCANDALS
}

Fernando González-Alonso ${ }^{1}$, José Luis Guzón-Nestar²

\begin{abstract}
RESUMEN
Se relaciona la moral, la ética, los Derechos Humanos, los Derechos del Niño y los valores, a través de la fundamentación que interrelaciona estos términos, en contraposición a los escándalos éticos como las guerras, los desplazamientos, el enriquecimiento ilícito, el abuso de los vulnerables, producidos por personas y organizaciones, que toman decisiones que afectan negativamente a la vida nacional e internacional de los pueblos, a través del ejercicio del poder y la búsqueda de sus propios intereses, contando como trasfondo, la necesaria formación de todos y la educación de los menores y el respeto a su interés superior.La filosofía moral como parte de la filosofía, se apoya en la metaética, la ética normativa y la ética aplicada. Estas aportan moralidad, justicia, verdad, creencias, lo correcto y lo incorrecto y abordan los desafíos morales de los temas de gran importancia. La ética y la moral, utilizados como términos intercambiables, contribuyen a la adquisición de valores como la honestidad, el respeto, la responsabilidad, etc., a través de razonamientos, procedimientos e implicaciones, donde los derechos se pueden ver afectados por las decisiones de personas y organismos, convirtiéndose en escándalos éticos alejados de la ética, los derechos y los valores. La relación entre la ética, derechos y valores nos conduce a las orientaciones que guían a personas, grupos sociales y Estados hacia el respeto de los Derechos Humanos, los Derechos del Niño y los valores humanos, respetando especialmente a los menores como "sujetos de derechos", donde la educación es un referente prioritario y necesario.
\end{abstract}

PALABRAS CLAVE: Ética, Derechos Humanos, Derechos del Niño, valores, escándalos éticos.

\section{RESUMO}

A moral, a ética, direitos humanos, direitos da criança e valores relaciona, através da fundação que interrelaciona esses termos, ao contrário de escândalos éticos, tais como guerras, deslocamento, enriquecimento ilícito, abuso de vulneráveis, produzido por indivíduos e organizações que tomam decisões que afetam negativamente a vida nacional e internacional dos povos, através do exercício do poder e na busca de seus próprios interesses, tendo como pano de fundo, a formação necessária para todos e educação de menores e respeito aos seus melhores interesses.A filosofia moral como parte da filosofia é baseada na metaética, na ética normativa e na ética aplicada. Estes contribuem para a moralidade, justiça, verdade, crenças, certo e errado e abordam os desafios morais das questões de grande importância. Ética e moral, usados como termos intercambiáveis, contribuir para a aquisição de valores como honestidade, respeito, responsabilidade, etc., através de raciocínio, procedimentos e implicações, em que os direitos podem ser afetados por decisões pessoas e organismos, tornando-se escândalos éticos longe da ética, direitos e valores. A relação entre ética, direitos e valores leva as diretrizes que orientam indivíduos, grupos sociais e estados

\footnotetext{
${ }^{1}$ Universidad Pontificia de Salamanca. (España).

${ }^{2}$ CES Don Bosco. Universidad Complutense de Madrid (España).

\begin{tabular}{l|l|l}
\hline Rev. Ciências Humanas & Frederico Westphalen, RS & Jan./abr. 2019 \\
\hline
\end{tabular}

Recebido em: 27/02/2019 $\quad$ Aceito em: 26/04/2019

Pg. 4-35
}




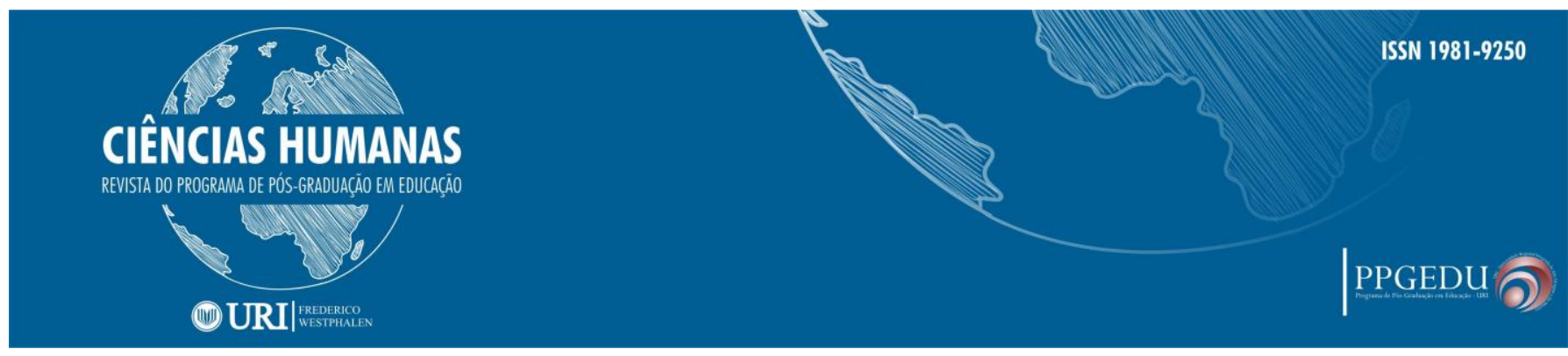

de respeitar os direitos humanos, direitos da criança e valores humanos, especialmente no que diz respeito às crianças como "sujeitos de direitos", Onde a educação é uma prioridade e referência necessária.

PALAVRAS-CHAVE: Ética, Direitos Humanos, Direitos da Criança, valores, escândalos éticos.

\begin{abstract}
It relates morality, ethics, Human Rights, Children's Rights and values, through the foundation that interrelates these terms, as opposed to ethical scandals such as wars, displacements, illicit enrichment, abuse of the vulnerable, produced by people and organizations, who make decisions that negatively affect the national and international life of the people, through the exercise of power and the pursuit of their own interests, with the necessary background, the global formation and the education of minors and the respect for their best interests. Moral philosophy as part of philosophy is based on metaethics, normative ethics and applied ethics. These bring morality, justice, truth, beliefs, right and wrong and address the moral challenges of the issues of great importance. Ethics and morals, used as interchangeable terms, contribute to the acquisition of values such as honesty, respect, responsibility, etc., through reasoning, procedures and implications, where rights can be affected by decisions of people and organisms, becoming ethical scandals away from ethics, rights and values. The relationship between ethics, rights and values leads us to the guidelines that guide people, social groups and States towards the respect of Human Rights, the Rights of the Child and human values, respecting minors as "subjects of rights" ", where education is a priority and necessary reference.
\end{abstract}

KEYWORDS: Ethics, Human Rights, Rights of the Child, values, ethical scandals.

\title{
INTRODUCCIÓN
}

Este artículo trata de relacionar la moral, la ética, los Derechos Humanos, los Derechos del Niño y los valores, a través del constructo que fundamenta e interrelaciona teóricamente estos términos, en contraposición a los escándalos éticos producidos por personas y organizaciones que realizan sin escrúpulos estas opciones, tanto a nivel nacional como internacional, a través del poder y búsqueda de sus propios intereses, teniendo como trasfondo la educación de los menores y su interés superior.

La composición del artículo subraya en al principio la filosofía moral como parte de la filosofía que destaca lo bueno de lo malo. La filosofía moral muestra la metaética, la ética normativa y la ética aplicada, como ramas destacables. La primera investiga lo qué es la moralidad, la justicia, la verdad y las creencias. La segunda señala lo que debemos hacer y no, lo correcto y lo incorrecto. Y la tercera, afronta temas de importancia moral, abordando los desafíos morales concretos de las personas en su día a día. 


\section{CIÊNCIAS HUMANAS}

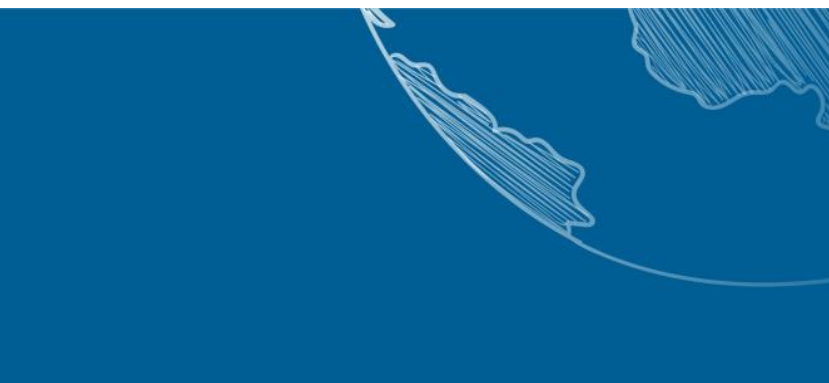

Continúa con la relación entre la ética y la moral, utilizados como conceptos intercambiables, al buscar valores comunes como la honestidad, el respeto, la responsabilidad, etc. Su uso implica distinguir lo correcto de lo incorrecto, sus consecuencias, razonamientos, implicaciones personales y los derechos que se ven afectados por las decisiones, sabiendo que el derecho implica deber y obligación a favor de la vida personal y de los demás, con sus respectivos ámbitos.

La relación entre la ética y derechos es otro apartado, donde las normas y los estándares de los derechos humanos se relacionan, para destacar cómo han de guiar las acciones, basadas en principios y directrices de los gobiernos, y de todos aquellos que nos vemos inmersos en ellos. Algunos Derechos que destacamos y relacionamos tienen que ver con La Declaración Universal de los Derechos Humanos, donde constan derechos personales, políticos, jurídicos, económicos, sociales, religiosos y culturales, destacando las tres generaciones de Derechos Humanos: Los de la Declaración de 1798, los Derechos del siglo XX, que están en la Declaración de 1948, los Derechos de la Tercera Generación, orientados con un matiz social a la paz, al desarrollo y al medio ambiente.

Especialmente, enfatizamos la importancia y relación con los Derechos del Niño, establecidos por la Convención, recogiendo aquí algunos datos históricos de interés, donde los menores son "sujetos de derechos".

Los niños y niñas tienen a la educación como derecho fundamental y Derechos del Niño, como expresión de reflexión y decisión ética presente en todos los tipos de Derechos explicitados.

Se hace un recorrido desde la ética a los escándalos éticos, pasando por los derechos, a través de la reflexión y decisiones, a partir de los dilemas y los comportamientos derivados tanto a nivel individual, como colectivo, destacando los escándalos éticos como las decisiones que asaltan los derechos y valores establecidos, buscando los beneficios propios.

En este sentido, y a modo de ejemplos, se presentan algunos escándalos éticos internacionales como la contaminación medioambiental, el bullying y ciberbullying, Trump y sus gestiones para levantar el muro con México y la separación de hijos y padres 


\section{CIÊNCIAS HUMANAS}

en la frontera, el problema complejo de Venezuela y los 264 millones de niños y niñas que no van a la escuela. A nivel nacional, algunos escándalos éticos como el de los "bebés robados", las "niñas de Alcásser” y las agresiones sexuales, torturas y asesinatos, los migrantes del "Aquarius", las mujeres que cobran menos por el mismo trabajo y los inmigrantes en centros de menores de Ceuta y Melilla son algunos de los casos que se analizan desde la perspectiva ética, de derechos y valores.

\section{LA MORAL FILOSÓFICA}

La filosofía moral es una rama de la filosofía que contempla lo que está bien y lo que está mal. Explora la naturaleza de la moralidad y examina cómo las personas deben vivir sus vidas en relación con los demás.

La filosofía moral tiene tres grandes ramas: metaética, ética normativa y ética aplicada.

Una rama, la metaética, investiga cuestiones generales como qué es la moralidad, la justicia, si hay verdad o no y cómo puedo justificar que mis creencias son mejores que las creencias de otros.

La metaética habla de la naturaleza de la ética y el razonamiento moral. Las discusiones sobre si la ética es relativa y si actuamos siempre por interés propio. Son ejemplos de discusiones metaéticas. De hecho, dibujar la distinción conceptual entre metaética, ética normativa y ética aplicada es en sí mismo un análisis "metaético".

Otra rama de la filosofía moral es la ética normativa. Responde a la pregunta de qué debemos hacer. La ética normativa se centra en proporcionar un marco para decidir qué es lo correcto y lo incorrecto. Tres marcos comunes son la deontología, el utilitarismo y la ética de la virtud.

La ética normativa está interesada en determinar el contenido de nuestro comportamiento moral. Las teorías éticas normativas buscan proporcionar guías de acción; procedimientos para responder la pregunta práctica (¿qué debo hacer?³). Las teorías morales de Immanuel Kant y Jeremy Bentham son ejemplos de teorías normativas

\footnotetext{
${ }^{3}$ Esta pregunta, junto a las otras dos que señala Kant en ¿Qué es la ilustración? (1784) constituye la clave de su antropología.
} 


\section{CIÊNCIAS HUMANAS}

que buscan proporcionar pautas para señalar un curso específico de acción moral: el imperativo categórico en el caso del primero y el principio de utilidad en el caso del segundo.

La última rama es la ética aplicada. Aborda temas específicos y prácticos de importancia moral, como la guerra y la pena capital. La ética aplicada también aborda los desafíos morales específicos que las personas enfrentan en su vida diaria.

La ética aplicada intenta tratar con campos específicos de la acción humana y elaborar criterios para discutir los problemas que puedan surgir dentro de esos campos. El campo contemporáneo de la ética aplicada se desarrolló a finales de los años sesenta y principios de los setenta. Hoy día es una parte próspera del campo de la ética. Numerosos libros y sitios web están dedicados a temas como ética empresarial, ética informática y ética de ingeniería.

Por lo tanto, ya sea que nuestro enfoque moral se base en preguntas generales, tenga un marco práctico o se aplique a dilemas específicos, la filosofía moral puede proporcionar las herramientas que necesitamos para examinar y vivir una vida ética.

\section{2. ÉTICA Y MORAL}

Muchas personas se molestan con la palabra "moralidad", pero se sienten bastante cómodos al usar el término "ética" e insisten en que hay una diferencia crucial entre las dos. Por ejemplo, algunas personas dicen que la ética se trata de normas externas impuestas socialmente, mientras que la moral se trata de la conciencia individual. Otros dicen que la ética es concreta y práctica, mientras que la moralidad es más abstracta o está vinculada de alguna manera a la religión. Entre los filósofos no hay una clara distinción acordada, y la mayoría de los filósofos usan los dos términos de forma más o menos intercambiable.

Ahora, no hay duda de que moral y ética se cruzan y se cruzan integralmente. Es decir, si somos personas morales y éticas, actuaremos sobre la base de un comportamiento de principios siguiendo virtudes como la honestidad, el respeto, la responsabilidad y la lealtad a la verdad. 


\section{CIÊNCIAS HUMANAS}

Gran parte de la confusión entre estas dos palabras se remonta a sus orígenes. Por ejemplo, la palabra "ética" proviene del francés antiguo (etique), del latín tardío (ethica) y del griego (ethos) y se refiere a las costumbres o filosofías morales. La "moral" proviene de la moral del latín tardío, que se refiere al comportamiento apropiado y los modales en la sociedad. Por lo tanto, los dos tienen significados muy similares, si no sinónimos, originalmente.

La moralidad y la ética del individuo se han estudiado filosóficamente desde los inicios, sin embargo, la idea de que la ética es un principio que se establece y aplica a un grupo (no necesariamente enfocado en el individuo) es relativamente nueva y se remonta principalmente al siglo XVII (John Locke). La distinción entre ética y moral es particularmente importante para los eticistas filosóficos.

En todo caso tanto moral como ética implican:

- Aprender lo que es correcto e incorrecto, y luego apuntar en la dirección de lo correcto.

- La mayoría de las decisiones ético-morales tienen consecuencias extendidas y la ética requiere sopesar las consecuencias de un curso de acción alternativo.

- La mayoría de las decisiones ético-morales no son blancas o negras, sino que se basan en el razonamiento a través de situaciones de conflicto usando algún estándar de orientación.

- La mayoría de las decisiones ético-morales tienen implicaciones personales.

- Finalmente, las decisiones ético-morales deben respetar los derechos de quienes se ven afectados por nuestras acciones.

John Locke en sus Tratados sobre el gobierno civil $^{4}$ presenta un interés social, ya que se preocupa de las relaciones del hombre con el Estado y con la sociedad, de ahí la importancia que otorga a los temas políticos.

El primer Tratado lo dedicó a la crítica de la tesis absolutista del "derecho natural" de los reyes, expuesta en el libro de Robert Filmer El Patriarca (1680).

\footnotetext{
${ }^{4}$ Two Treatises on Government (1689).
} 


\section{CIÊNCIAS HUMANAS}

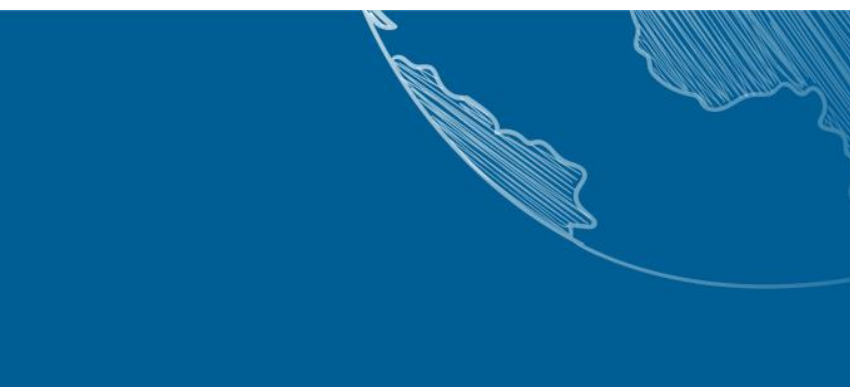

El segundo Tratado contiene la parte positiva de la doctrina lockeana, su primer paso consiste en exponer lo que él mismo entiende por poder político, que a diferencia de Filmer, distingue el poder del amo, del señor sobre sus hijos o criados respectivamente.

El derecho implica deber, el estado de naturaleza tiene su ley que a todos obliga, nadie ha de atentar ni contra la vida de otro, ni contra la salud, ni contra la libertad, ni contra las demás propiedades de otro, nadie puede invocar una libertad que nos autorice a destruirnos mutuamente.

En las teorías lockeanas bien podemos observar tanto una separación de ética y moral, como un precedente de los derechos humanos, ya que para Locke la libertad, la salud y la propiedad serían vienes inviolables.

Aquí enlazamos con el tema de nuestro interés: los derechos humanos.

\section{3. ÉTICA Y DERECHOS}

Tradicionalmente, las normas de derechos humanos están destinadas a guiar las acciones de los gobiernos, mientras que la ética abarca mucho más la preocupación por las acciones específicas, las inspiraciones y las relaciones de los trabajadores, investigadores y organizaciones individuales. Los principios éticos que deben guiar nuestro trabajo deberían ser producto de una consulta amplia, y estar redactados por representantes de organismos profesionales y organizaciones, y existen en forma de directrices y códigos de conducta propuestos.

Por ejemplo, la Asociación Médica Mundial adoptó el Código de Helsinki en 1964 (MANZINI, 2000). El Código de Helsinki, que inicialmente se centró en la investigación con sujetos humanos, fue el precursor del campo de la bioética, que abarca la investigación en ciencias de la vida y la ética de la práctica de la salud.

En los Estados Unidos, la bioética, desarrollada a fines de los años sesenta y principios de los setenta, enfatizaba la prioridad central de la autonomía individual, reflejando el individualismo de la cultura estadounidense, en contraste con la solidaridad social característica de otras culturas.

Una característica clave de las directrices éticas, como se demostró recientemente con la investigación con células madre y las vacunas contra el VIH, es que pueden 


\section{CIÊNCIAS HUMANAS}

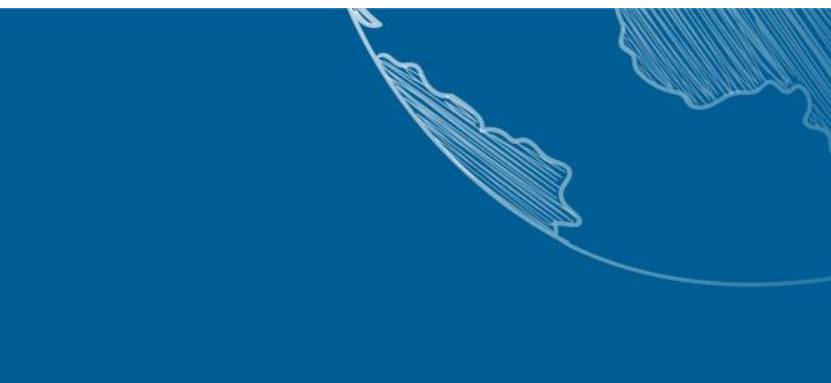

ajustarse o redactarse rápidamente para enfrentar los desafíos científicos y humanos en evolución, lo que permite la variación regional o nacional según sea necesario.

En contraste, las normas y los estándares de derechos humanos tienden a ser redactados por representantes de los gobiernos, negociados en foros políticos e incorporados al cuerpo del derecho internacional en forma de tratados internacionales que imponen obligaciones legales a los gobiernos que los ratifican. Si bien estos procesos permiten al derecho de los derechos humanos una permanencia y legitimidad útiles para involucrar a los gobiernos e instituciones de poder (PECES BARBA, 2014), existe una menor flexibilidad y una adaptación menos rápida posible que con las pautas éticas.

La Declaración Universal de los Derechos Humanos de 1948, aunque con una forma significativa a través de las habilidades diplomáticas de la estadounidense Eleanor Roosevelt, refleja los principios de muchas culturas y tradiciones y el consenso alcanzado entre los gobiernos sobre qué derechos deberían existir. Las convenciones legales internacionales que surgieron después de la declaración obligan a los gobiernos de los países que los suscriben, y al hacerlo afectan lo que se tiene y se debe hacer para proteger la salud.

$\mathrm{Al}$ asomarnos a esta temática, no podemos preterir la codificación más importante del consenso internacional sobre la dignidad humana: la Declaración Universal de los Derechos Humanos, proclamada por la ONU el 10 de diciembre de 1948. La Declaración consta de un Preámbulo (con siete "Considerando", una especie de postulados previos) y 30 artículos muy breves en que la Asamblea General de la ONU proclama ese "ideal común por el que todos los pueblos y naciones deben esforzarse...". Hay derechos personales (igualdad, vida, no esclavitud, libertad, no tortura, seguridad); derechos políticos (asilo político, residencia, reunión, opinión, voto, casarse, participar en la vida ciudadana, nacionalidad...); derechos jurídicos (protección, juicio imparcial, presunción de inocencia...) y derechos económicos, sociales, religiosos y culturales (trabajo, salario, sindicación, cultura, educación, libertad religiosa, descanso...) (SORIANO DÍAZ , 2014, 45-53).

Se puede decir que hay tres generaciones de Derechos Humanos: 


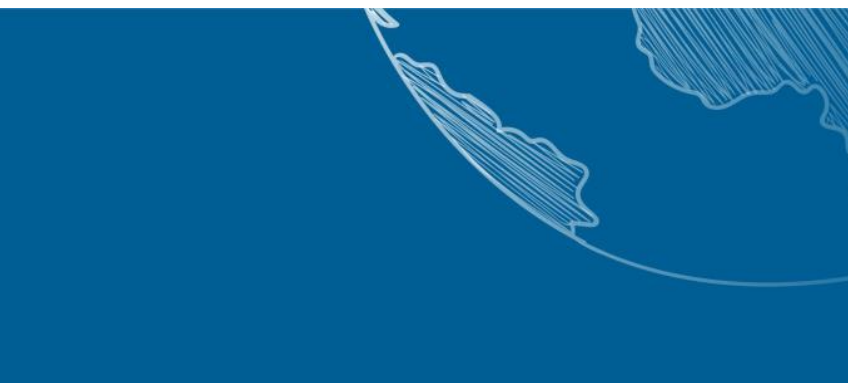

a) Los de la Declaración de 1798 (la Revolución Francesa) que tienen como eje la libertad.

b) Los Derechos del siglo XX, que están en la Declaración de 1948, y

c) Los Nuevos Derechos, o Derechos de la Tercera Generación, que tienen un carácter social supranacional (a la paz, al desarrollo, al medio ambiente).

Además. se han aprobado documentos de derechos sectoriales: Derechos del Niño, por ejemplo.

Ahora bien, desde 1948 hasta hoy, la ONU y los movimientos sociales han intentado desarrollarlos en dos líneas:

a) Trabajar por unas garantías más efectivas de los derechos reconocidos. Así se llega a los Pactos Internacionales de 1966.

b) Buscar respuestas para nuevas aspiraciones de la humanidad, nacidas de la mundialización creciente y de las exigencias de justicia y de paz a escala planetaria. Culmina en los Derechos de la Tercera Generación (derecho al desarrollo, derecho al medio ambiente, derecho a la paz).

Los Derechos de Tercera Generación, de los que se comienza a hablar por los años 1970, surgen en el marco de emancipación de los pueblos dominados y colonizados. Son derechos que desbordan, con frecuencia, el ámbito estrecho de las naciones y estados. Los documentos más interesantes son: Declaración sobre el derecho al desarrollo (ONU, 4 de diciembre de 1986); Documentos de la Cumbre de Río (1992) sobre desarrollo y medio ambiente; Declaración sobre las Sociedades para Vivir en Paz (1978); Declaración sobre el Derecho de los Pueblos a la Paz (1984). Son también muy interesantes los documentos de las Cumbres internacionales desde 1993: Cumbre de los Derechos Humanos. Celebrada en Viena en 1993; Cumbre sobre la Población. El Cairo, 1994; Cumbre sobre el Desarrollo Social. Copenhague, 1995; Cumbre sobre la Mujer. Pekín, 1995. Cumbre sobre los asentamientos humanos. Estambul, 1996; Cumbre Río (la Cumbre de Río, cinco años después). Nueva York, 1997; Cumbre sobre el Cambio Climático. Kioto, 1997; Cumbre sobre la esclavitud, Durban, Sudáfrica, septiembre de 2001; Cumbre Mundial sobre el Desarrollo Sostenible en Johannesburgo (2002); Conferencia de las Naciones Unidas sobre el Desarrollo Sostenible en Rio de Janeiro (2012) y la Cumbre de las Naciones Unidas sobre el Desarrollo Sostenible en Nueva York (2015). 


\section{CIÊNCIAS HUMANAS}

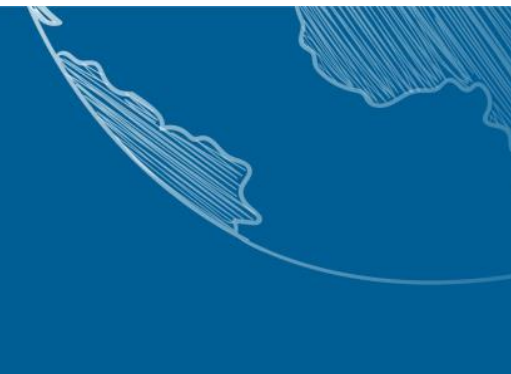

\section{LOS DERECHOS DEL MENOR}

En este camino de los Derechos Humanos, revisten un particular interés para nosotros los Derechos del Niño. El 20 de noviembre de 1959 se aprobó la Declaración de los Derechos del Niño de manera unánime por todos los setenta y ocho Estados miembros de la ONU. Esta fue adoptada y aprobada por la Asamblea General de las Naciones Unidas mediante su resolución 1386 (XIV) en la Resolución 1386 (XIV).

El «menor» es una construcción social construida por los adultos a lo largo de la historia. La evolución de la infancia como una categoría social ha ido perfilándose con el reconocimiento, definición, desarrollo y evaluación del niño, así como con las intervenciones de los adultos para facilitar su desarrollo (AUSTIN, DWYER, FREEBODY, 2003).

Resulta complejo definir qué es ser «menor». Abordarlo requiere una triple actitud inquisitiva: rastrear la genealogía de las prácticas de relacionarse con ellos en la vida y en las instituciones; relacionar dichas prácticas con el funcionamiento general de la sociedad y analizar los discursos sobre los «menores» desde las creencias, pasando por los discursos y aterrizando en los modelos a modo de representaciones ideales sobre lo que son y deseamos que sean (GIMENO SACRISTÁN, 2003, p. 20).

El estudio de las infancias reales (las condiciones de vida familiares y sociales del niño, el medio social al que pertenecen, los sistemas de vida de los adultos con los que conviven, las condiciones de vida institucionalizada como los procesos de escolarización), el estudio de las visiones científicas y no científicas de la infancia (los discursos acerca de la infancia, los discursos acerca de cómo debe ser el ser humano y las explicaciones sobre cómo las condiciones de vida construyen al ser humano en general), y el estudio de los discursos acerca de cómo puede ser la infancia (ideas que proyectan los adultos sobre los «menores» y las aspiraciones de mejora de la humanidad), son los determinantes de la construcción de la infancia (GIMENO SACRISTÁN, 2003, p. 21), que aquí señalamos sin que podamos entrar en su abordaje, con excepción de la pulsión ética, temática central que aborda el artículo. 


\section{LOS DERECHOS DEL MENOR: DE SUJETO DE DERECHOS A SUJETO SOCIAL DE DERECHOS. DATOS PARA LA HISTORIA}

Igual que los adultos de todas las especies suelen tener una disposición favorable hacia las crías (DEL VAL, 2004, p. 24), los adultos de la especie humana han pensado que niños, adolescentes y jóvenes son el futuro de la sociedad. Pero dicha actitud ha pasado por muchas fases y con frecuencia se olvidó que los niños eran sujetos de derechos. Eso en la sociedad actual, aunque la realidad dista mucho de haber llegado a una situación óptima, grandes capas de la población lo van teniendo mucho más claro.

ARIÈS (1987), con su obra El niño y vida familiar en el Antiguo Régimen (1960), nos alertó sobre la desconsideración que había habido hacia este segmento de la población durante siglos. Desde su punto de vista, hasta el siglo XVIII no aparece un sentimiento de consideración hacia la infancia, semejante al que podamos tener en la actualidad y que a los niños hasta entonces se les consideraba como seres divertidos no muy diferentes de los animales ${ }^{5}$.

Desde el punto de vista científico, se puede asegurar que hasta el XVII no aparecen más que observaciones esporádicas sobre la infancia en los libros de educación (Héroard, Cheselden...). A partir del XVIII se inicia una reflexión con observaciones más sistemáticas (Tiedemann, Itard, Feldmann, Quételet, Darwin, Taine...) que culminarán en los estudios científicos de psicología en que se considera al niño como un ser humano en una etapa de desarrollo concreta (Preyer, Stanley May.... ${ }^{6}$. Según Ariès el siglo XVII, pues, es el siglo del «descubrimiento de la infancia». Hoy algunas tesis de Ariès se han demostrado desenfocadas por trabajos recientes (M. Golden, Children and Childhood in Classical Athens, 1990; D. A. Bidon y D. Lat, Les enfants au Moyen Age, 1997, o L. Pollock, Muchachos olvidados. Las relaciones entre padres e hijos entre 1500-1990

\footnotetext{
${ }^{5}$ Cf. J. DELVAL, o.c., 25. Así mismo, según Donzelot, la revalorización de la infancia tiene que ver, a partir del siglo XVIII, con la convergencia de dos estrategias sociales: la difusión entre la burguesía de la medicina doméstica responsabilizando a los padres directamente del cuidado de los menores y la búsqueda de la «economía social» que pretendía dirigir la vida de los pobres con la vigilancia directa de sus vidas para disminuir el costo social de su reproducción. 


\section{CIÊNCIAS HUMANAS}

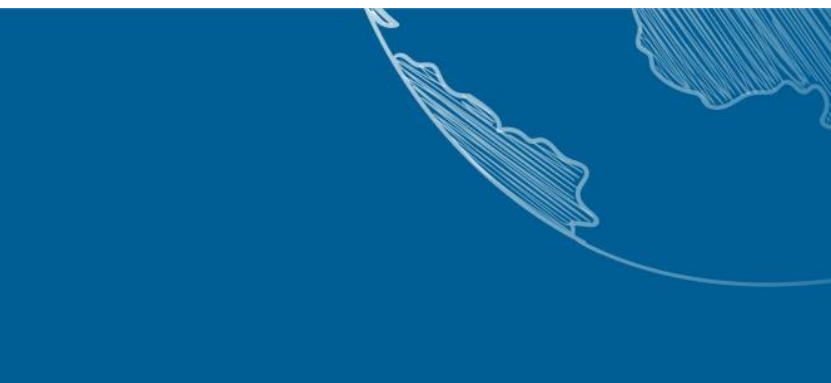

(BAJO-J.-L. BETRÁN, 1998, p. 13), pero no cabe duda de que el proceso de toma de conciencia ha sido lento y nos conduce hasta una época muy reciente. Así mismo, según J. Gimeno Sacristán (2003, pág. 31), «estudios como los de Ariès (1987) han sido criticados porque sus deducciones acerca de cómo eran los niños y las relaciones que los adultos mantenían con ellos se basan en representaciones, y no tanto en realidades de la infancia, que, por otro lado, non son representativas de toda la infancia, sino de determinados grupos sociales» (GIMENO SACRISTÁN, 2003, p. 31).

Hoy hablamos de «menores». Aunque en nuestra tradición se ha hablado de niños y niñas, adolescentes (los fanciulli, o ragazzi de Don Bosco) realmente tenemos que adecuar nuestro lenguaje al que refiere la sociedad. Hoy se habla de «menores». Puede que no estemos familiarizados con el término, pero es evidente que es más riguroso y apropiado en términos sociales y jurídicos que otros que se han venido utilizando: «Cuando los juristas hablamos del menor o de los derechos del menor, nos estamos refiriendo a aquellos derechos que corresponden no sólo al niño/a en cuanto tal, sino también a los adolescentes. Resulta evidente que una persona de dieciséis años o de diecisiete años no es propiamente un niño, pero sí es un menor y, como tal, es titular de todos los derechos que corresponden a los menores (derechos que, en muchos aspectos, no son iguales a los derechos de los mayores) y, además, debe ser objeto de una especial protección en cuanto persona en fase de desarrollo y, por ello, especialmente vulnerable» (ARTEAGABEITIA et al, 2005, p. 3).

Y hablamos de «menores» vinculando de un modo muy significativo lo específico de esta etapa con la consideración acerca de los derechos que tienen estas personas. Es bonito también saber cuál ha sido la historia de la toma de conciencia social de estos derechos. Los principales hitos han sido los siguientes:

- En 1919 se creó la Sociedad de Naciones y la Organización Internacional del trabajo, que desempeñaron un papel fundamental en la protección del menor.

- El año 1920 Englantyne Jebb fundó la Union Internationale de secours aux enfants (UISE). Esta mujer redactó la Declaración de Ginebra de 1923. Consta de cinco puntos que reconocen la necesidad de la alimentación, de evitar la explotación, etc. La Asamblea de Naciones Unidas acogió en 1924 esta declaración. 


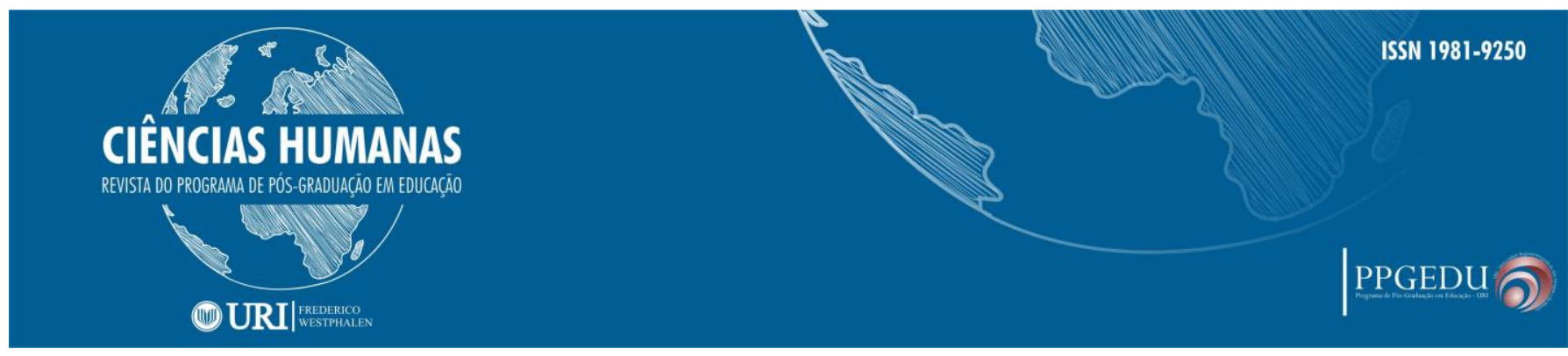

- Finalizada la II Guerra Mundial, en 1946, se creó UNICEF (Fondo de las Naciones Unidas de Ayuda a la Infancia).

- En 1948 se promulga la Declaración Universal de Derechos Humanos en que se reconoce el derecho de la maternidad y de la infancia a una ayuda y asistencia especial (art. 25.2)

- Posteriormente, en 1959, la Asamblea General de Naciones Unidas aprobó una resolución titulada «Declaración de los derechos del niño», en la que se proclamaban diez principios que ampliaban la Declaración de Ginebra (1924). La innovación más importante, según los estudiosos, entre estas dos Declaraciones (1924 y 1959) es que en ésta última el niño pasa de ser objeto a ser sujeto de derechos.

- En 1966 en Naciones Unidas se adoptan los conocidos Pactos Internacionales que entrarían en vigor en 1976. Estos pactos reconocían el derecho de todo niño a ser objeto de una protección especial, debido a su condición de «menor».

- El 20 de noviembre de 1989 la Asamblea General de Naciones Unidas aprobaba por unanimidad la Convención de los Derechos del Niño. Su entrada en vigor fue el 3 de septiembre de 1990, al ser firmado por el vigésimo estado. En España su entrada en vigor se produjo el 5 enero de 1991 (BOE de 31 de diciembre de 1990) (PAJA BURGOA, 1998, pp. 52-56). En realidad, «la declaración de 1959 estuvo lastrada por grandes carencias y sin obligaciones jurídicas para los Estados participantes. Tan sólo la Convención de 1989 tuvo carácter de ley internacional y los Estados adquirieron el compromiso de asegurar su aplicación y las medidas necesarias para su promoción» (MARTÍNEZ RODRÍGUEZ, 2005, p. 50). La convención reconoce derechos civiles, políticos, económicos y culturales para los «menores» y sigue siendo la principal herramienta internacional de trabajo internacional por su diferente orientación de la legislación y porque encierra una concepción vanguardista sobre los derechos de la niñez.

A pesar del recorrido histórico señalado, ni los principios ni las disposiciones establecidas por la Convención han logrado afectar las estructuras de los distintos países. La visión predominante sigue siendo la que considera al «menor» como objeto social pasivo de protección y cuidado.

Como indica Rodríguez-Martínez (2005), las definiciones del niño como «sujeto de derechos» son insuficientes al no considerar realmente el contexto en el que viven y su práctica actual. La conciencia social predominante se concentra en la satisfacción de algunas necesidades básicas y concentra la responsabilidad de su satisfacción en el Estado. En definitiva, una visión paternalista y verticalista adulta que limita las 


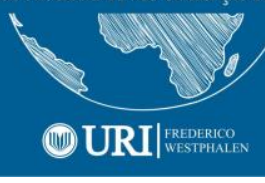

potencialidades endógenas del niño y que requiere ir más allá de la idea de sujeto de derechos, porque sólo en la medida en que vaya desarrollándose como sujeto social, podrá ir afirmándose como sujeto de derechos (p. 53).

Para ello, se requiere la aplicación de nuevas políticas educativas (Hart, Himes y Lanstow (1998, p. 50) que pasan por reconsiderar el papel de los medios de comunicación y la creación de programas y estructuras escolares para los centros democráticos.

\section{LA EDUCACIÓN COMO DERECHO FUNDAMENTAL}

La expresión más clara de la pulsión ética, temática central de este artículo, la encontramos en la Declaración Universal de los Derechos Humanos, La Convención de los Derechos del niño y en el reconocimiento del valor dignificante de la educación. Desde entonces, la idea de dignidad humana y educación quedaron asociadas estrechamente. En el Art. 26.1 de la Declaración de Derechos Humanos eleva la condición del menor y alumno ${ }^{7}$ y la posterior Declaración de derechos del niño de 1959 señala la educación como un derecho específico de la infancia. ${ }^{8}$

Así mismo, los artículos 28 y 29 de la Declaración recogen el derecho a la educación como derecho fundamental. Dice el artículo 28: «Los Estados Partes reconocen el derecho del niño a la educación $\mathrm{y}$, a fin de que se pueda ejercer progresivamente y en condiciones de igualdad de oportunidades ese derecho, deberán en particular...» (ÁLVAREZ VÉLEZ \& CALVO BLANCO, 1998, pp. 16-17).

\footnotetext{
${ }^{7}$ «Toda persona tiene derecho a la educación. La educación debe ser gratuita, al menos en lo concerniente a la instrucción elemental y fundamental. La instrucción elemental será obligatoria. La instrucción técnica y profesional habrá de ser generalizada; el acceso a los estudios superiores será igual para todos, en función de los méritos respectivos...».

${ }^{8}$ (Principio número siete): «El niño tiene derecho a recibir educación, que será gratuita y obligatoria por lo menos en las etapas elementales. Se le dará una educación que favorezca su cultura general y le permita, en condiciones de igualdad de oportunidades, desarrollar sus aptitudes y su juicio individual, su sentido de responsabilidad moral y social, y llegar a ser miembro útil de la sociedad. El interés superior del niño debe ser el principio rector de quienes tienen la responsabilidad de su educación y orientación; dicha responsabilidad incumbe, en primer término, a sus padres. El niño debe disfrutar plenamente de juegos y recreaciones, los cuales deben estar orientados hacia fines perseguidos por la educación; la sociedad y las autoridades públicas se esforzarán por promover el goce de este derecho».
} 


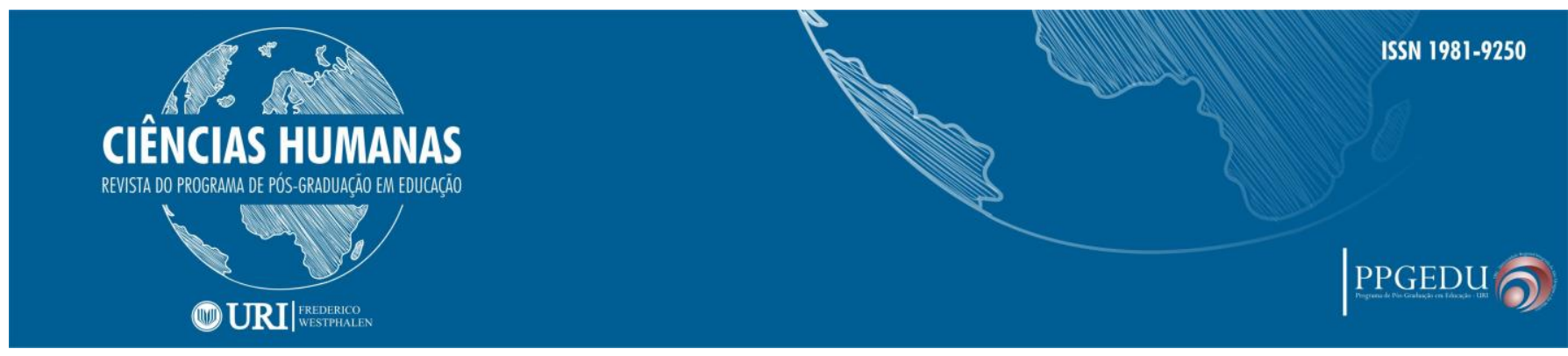

A continuación, se detallan medidas que pueden contribuir a la efectiva aplicación del articulado. Contiene este artículo cuatro ideas básicas: el derecho a la educación, la vigilancia de la disciplina escolar, la cooperación internacional en la materia y los escándalos éticos que se producen.

Todos somos conscientes de las ventajas que se derivan de la asunción de este derecho. En primer lugar, muchos estudios vinculan el desarrollo de la educación, junto con la salud, como un elemento que contribuye a aflojar el yugo de la pobreza. En segundo lugar, la educación se presenta como un requisito imprescindible para hacer frente a los problemas medioambientales. Y, tercero, la ampliación de la educación se relaciona muy estrechamente con el descenso (control) de la natalidad. (PAJA BURGOA, 1998)

Es conocida la historia del absentismo escolar en épocas precedentes y en la actualidad todavía en ciertas zonas geográficas, ya que,

\begin{abstract}
«el número de niños privados de acceso a la educación era muy elevado. La mayoría pasaba de los juegos infantiles a incorporarse al oficio del padre, ya fuese un trabajo agrícola o artesanal. El niño no se alfabetizaba sólo en las aulas, sino también en las tiendas y en los talleres donde era adiestrado precozmente y donde adquiría otras competencias: artesanales, artísticas, mercantiles... [...]. No obstante, el problema mayor se les planteaba a los niños no encuadrados en ninguna actividad, ni educativa, ni productiva: los casos de los niños mendigos, generalmente huérfanos, cuyo número crecía de forma espectacular tras cada período de carestía o epidemia, que se agrupaban en pequeñas bandas y sobrevivían o morían dependiendo de la caridad pública». (PAJA BURGOA, 1998, p.77-78).
\end{abstract}

\title{
7. DE LA ÉTICA A LOS ESCÁNDALOS ETICOS
}

El ejercicio normalizado a favor de las decisiones éticas, soportan un proceso de razonamiento moral, donde el análisis de los dilemas que se presentan concluye en discernimientos y conductas éticas aplicadas por individuos y por organizaciones. Ni la metaética, que relaciona y relativiza la propia naturaleza de la ética y promueve razonamientos morales situados en la corrección o en el interés personal de las conductas; ni la ética normativa, que como hemos visto, responde a la cuestión de lo que debemos hacer, dando sentido a nuestras actuaciones; ni la ética aplicada, que destaca desafíos morales de situaciones humanas muy importantes, son tomadas especialmente en cuenta cuando personas y organismos, optan por 


\section{CIÊNCIAS HUMANAS}

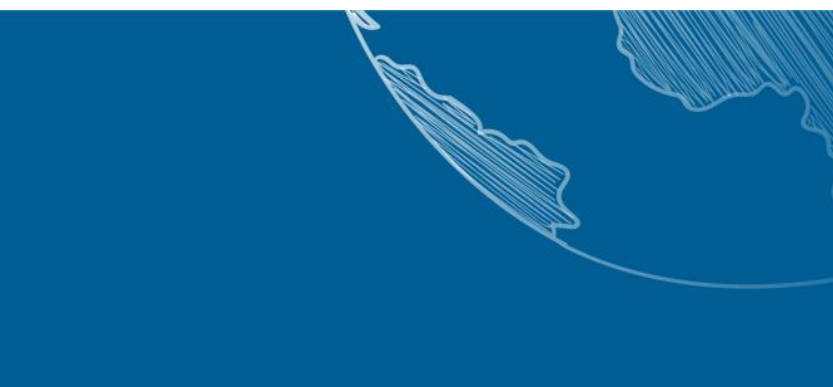

determinadas decisiones, donde el abuso del poder y los intereses particulares derivan en escándalos éticos.

La existencia de los Derechos Humanos, los Derechos del Niño y de valores humanos, como hemos ido explicando y argumentando, no han sido soporte moral suficiente para tomar las decisiones adecuadas que los consigan y aporten a la sociedad y sus organizaciones, más bien ha supuesto en muchos casos como veremos a continuación, un listado de actuaciones humanas bochornosas, con consecuencias muy delicadas y negativas, alejadas de Derechos y valores. El afán natural de la sociedad por alcanzarlos, hace que al no conseguirlos, se produzcan actitudes de fracaso y frustración.

\section{Ética y razonamiento moral: los dilemas}

La ética soporta un proceso de razonamiento moral aplicado a través de los dilemas frecuentes. Los dilemas morales han estado siempre presentes en el proceso de reflexión y de decisión de individuos e instituciones, con el fin de optar por la alternativa más correcta, que libre de intereses, les beneficie con comportamientos adecuados, aunque no siempre las consecuencias e implicaciones éticas (Montuschi, 2002), pudieran coincidir en un mismo nivel de gustos y deseos.

Es de desear que, en el proceso de razonamiento para la decisión ante un dilema, el criterio ético sea fundamental, lo que ayudará a facultar la racionalidad ética en las decisiones que se tomen (Izquierdo, 2009). Otro criterio que, en el ámbito de la educación superior, ayuda a tomar decisiones éticas es el aprendizaje servicio, tanto en cuanto que favorece la asimilación y aplicación de valores humanos y morales, desarrollando la destreza para recibir delegaciones con carácter de corresponsabilidad (Arratia, 2008). Según Zaror y Vergara (2008), se requiere de una sensibilidad y competencias éticas que favorezcan la identificación y análisis de los dilemas, como ejercicio previo a la decisión individual o participativa, que reafirme una ética desde la justicia y la corrección.

\section{El comportamiento ético del individuo y de las organizaciones}

Las decisiones individuales o participativas de las organizaciones requieren de unos valores y percepciones vinculadas al ámbito del espacio laboral que comparten. El sentirse a gusto, motivado y satisfecho en el trabajo resulta fundamental para contar con las condiciones básicas para emitir un juicio ético que lleve a consecuencias deseables. 


\section{CIÊNCIAS HUMANAS}

Lo que requiere un aprendizaje, capacitación y entrenamiento adecuado en el entorno del trabajo (Furnham, 2001). La convivencia diaria, el clima institucional y la toma de decisiones participativa, han de ser valoradas y mejoradas periódicamente, por las implicaciones decisorias personales e institucionales que tiene, cuando individual y grupalmente se sienten y encuentran bien.

Existen comportamientos éticos en una taxonomía (Córdoba, 2005) que, desde el entorno de la educación superior, favorecen su estudio, formulan lineamientos y servir para la capacitación necesaria en las implicaciones empíricas de un código ético que favorezca un buen desenvolvimiento (Romero, 2006).

Como hemos señalado; no siempre los razonamientos y las decisiones tomadas son éticas, y no siempre llevan a comportamientos morales. Según Bañón et al. (2011), tienen la potestad de evitar determinados comportamientos no éticos, con consecuencias, en muchos casos, inhumanas.

Los escándalos éticos están relacionados con decisiones y comportamientos comprometedores desde el ámbito laboral, político, de los negocios, social, educativo, religioso, económico, etc. Así, consecuencias globales son las guerras, el hambre, la corrupción, la pobreza, la desigualdad, el desempleo, la falta de vivienda, las injusticias, etc. Otros escándalos éticos según Kliksberg (2011) tienen que ver con el déficit de agua potable y de educación, la insuficiencia sanitaria, la Generación Perdida como consecuencia de la crisis económica, las elevadas tasas de mortalidad infantil y materna, el cambio climático, el calentamiento global, la discriminación de género, etc. En todas ellas se percibe un déficit de reflexión y procedimientos éticos, así como de Derechos y valores.

Ante las consecuencias escandalosas por las malas decisiones éticas, cabe un profundo ejercicio de educación en valores, apoyada en una axiología educativa que es casi una tautología (González-Alonso, \& Guzón-Nestar, 2017). 


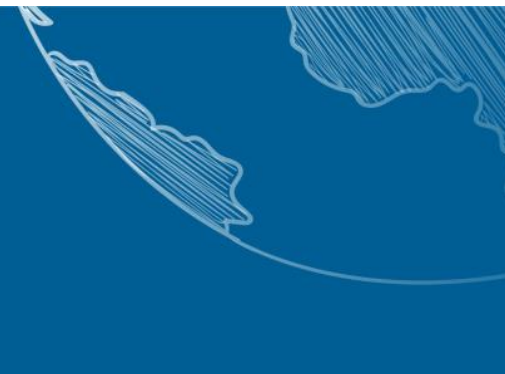

\section{ESCÁNDALOS ÉTICOS, DERECHOS Y VALORES}

Presentamos a continuación una selección de escándalos éticos internacionales y nacionales como prueba del mal ejercicio de la ética y la moral, por el abuso del poder y de los intereses personales y colectivos, buscando el favor de éstos y el perjuicio e injusticias globales del resto.

Todos los días se producen nuevos escándalos éticos que nos hacen pensar sobre el bien y el mal, sobre lo bueno y lo malo, sobre lo que se ha de hacer y no. Todos nos encontramos con dilemas, que nos llevan a comportamientos buenos o malos según hagamos de un uso responsable o irresponsable de nuestra libertad y responsabilidad.

El proceso reflexivo para determinar lo ético de lo no correcto, requiere unos criterios amparados en la conciencia individual o colectiva y en cumplimiento y respeto a los Derechos Humanos y a los Derechos del Niño.

Los primeros se recogen en la Declaración Universal de los Derechos Humanos (DUDH) aprobada por la Asamblea de las Naciones Unidas en 1948 como Proyecto común de todas las naciones, concretando los 30 Derechos Humanos fundamentales que han de ser protegidos por todos, como el derecho a la vida, a la libertad, nacionalidad, libertad de pensamiento, de conciencia y de religión; el derecho a trabajar, a la educación, al alimento y vivienda, y a la participación democrática.

Los segundos en la Convención sobre los Derechos del Niño (CDN) de 1990, que como tratado internacional reconoce los derechos de los menores, y exige a los Estados y gobiernos a respetarlos y acatarlos. Excepto Estados Unidos, todos los países están a favor de los 54 artículos que forman los Derechos del Niño basados en derechos económicos, sociales, culturales, civiles y políticos, además de tres protocolos relativos a la venta y prostitución infantil, a la participación de los menores en movilizaciones armadas y al procedimiento para presentar denuncias ante el Comité de los Derechos del Niño.

Por otro lado, los valores humanos, son otro importante criterio de referencia para vivir y decidir éticamente, al ser ideas valiosas en sí mismas, atrayentes y motivantes para el desarrollo vital de las personas. 


\section{CIÊNCIAS HUMANAS}

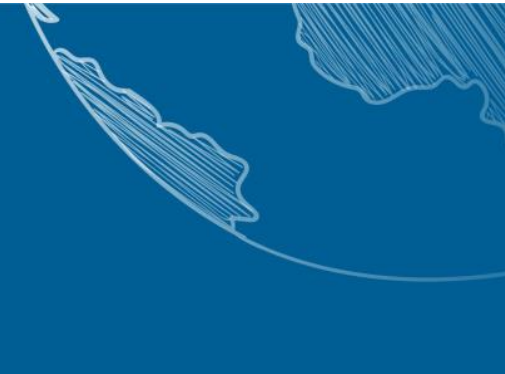

Si la ética hace referencia al comportamiento humano responsable, los deberes y las obligaciones, y la moral tiene que ver con dignidad de la persona, apoyada en las costumbres diarias, se definen entonces la bondad o la maldad de nuestras decisiones y acciones. Los valores como principios propios de personas o colectivos son características morales relacionadas a la persona como la libertad, la responsabilidad, la humanidad, la solidaridad, etc. Para una educación ética y moral ha de darse una educación en valores. Las tres, ética, moral y valores, se encuentran directamente vinculadas a los Derechos Humanos y los Derechos del Niño.

Veamos algunos escándalos éticos, ante opciones y decisiones inmorales individuales o colectivas, contrarias a los Derechos Humanos fundamentales, a los Derechos del Niño y a algunos valores humanos, que como ejemplos destacamos.

\section{Escándalos éticos a nivel internacional}

Resulta complicado limitar los escándalos éticos, el listado se hace interminable.

Los escándalos éticos que presentamos vulneran algún Derecho Humano fundamental, algún Derecho del Niño y se aleja de valores humanos. Esto es lo que se destaca y relaciona tras indicar cada escándalo ético.

\section{La contaminación medioambiental:}

Es un hecho del que no somos conscientes que está en nuestras manos resolver. Nuestra escasa concienciación de reciclar, de no contaminar, de sustituir materiales nocivos por otros que respetan el medio ambiente, mares, naturaleza y planeta, nos avoca a la destrucción del medio ambiente. Aunque cada vez nos concienciamos más del problema, no buscamos ni aplicamos todos las soluciones con la urgencia que tiene.

La actuación a favor de la contaminación medioambiental va en contra del art. 3 de los derechos humanos: "Todo individuo tiene derecho a la vida, a la libertad y a la seguridad de la persona"; del art. 25: "Derecho a asegurar la familia, la salud y el bienestar" y del art. 28: "Derecho a un orden social e internacional en los derechos y 


\section{CIÊNCIAS HUMANAS}

REVISTA DO PROGRAMA DE PÓS-GRADUAÇ̄o EM EDUCAC̄̄O

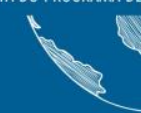

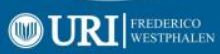

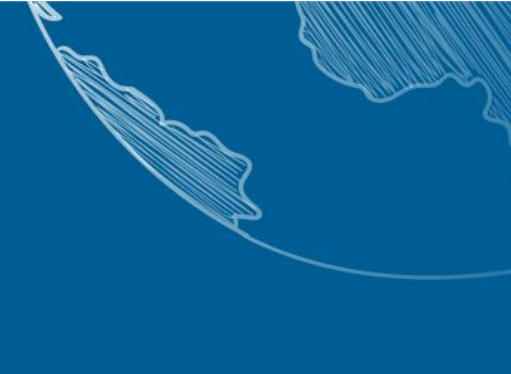

libertades". De igual forma se relacionan con los Derechos del Niño: "El Estado debe proteger al niño contra el trabajo nocivo para su salud, educación o desarrollo" (art. 32).

Los valores como el compromiso, la naturaleza, la sociabilización, el compromiso, la corresponsabilidad son valores contrarios al escándalo.

\section{Bullying y Ciberbullying:}

El Acoso escolar o bullying es un problema de gran actualidad en las escuelas que afecta al entorno personal, familiar y social. Hay muchas noticias en todos los países que dan fe de ello. En España según datos de 2018 afecta al 10\% del alumnado, siendo uno de cada cuatro, ciberbullying ${ }^{9}$ Normalmente los más afectados por estas prácticas intimidatorias suelen ser el alumnado diverso de origen extranjero, con alguna discapacidad, o de opción sexual diferente a la heterosexual.

La actuación contra las víctimas, el abuso de los agresores con la colaboración, en mucho casos, de los espectadores, es contraria a algunos Derechos Humanos: el art. 1: "Todos los seres humanos nacen libres e iguales en dignidad y derechos, y deben comportarse fraternalmente los unos con los otros"; el art., 2: "Toda persona tiene derechos y libertades, sin distinción alguna"; el art. 3 ya expresado y art. 12: "No será objeto de injerencias arbitrarias en su vida privada, su familia, su domicilio. No atacar a su honra o reputación".

También hacen frente a los Derechos de la Infancia en los artículos 2: “Todos los derechos deben ser aplicados a todos los niños, sin excepción alguna, y es obligación del Estado tomar las medidas necesarias para protegerle de toda forma de discriminación"; el art. 16: "Todo niño tiene derecho a no ser objeto de injerencias en su vida privada, su familia, su domicilio y su correspondencia, y a no ser atacado en su honor" y el art. 17: “El Estado protegerá a los niños de los medios de comunicación”. En esta relación, los

\footnotetext{
${ }^{9}$ Fundación ANAR y Mutua Madrileña (2018). III Estudio sobre acoso escolar y ciberbullying según los afectados. Recuperado de https://www.anar.org/iii-estudio-acoso-escolar-y-ciberbullying-segun-losafectados/
} 


\section{CIÊNCIAS HUMANAS}

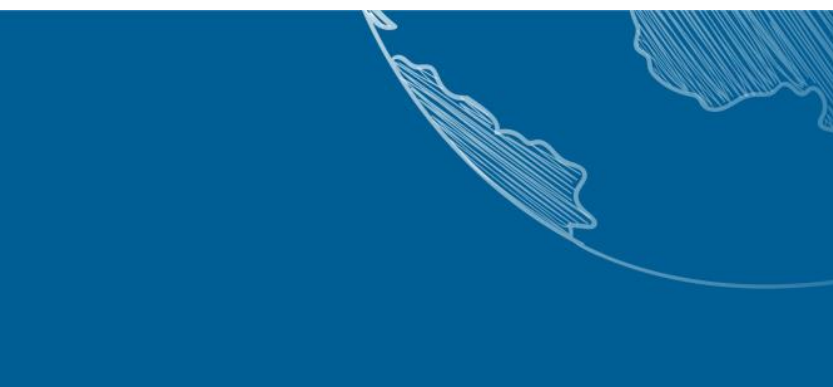

valores de seguridad física, colaboración y compañerismo, se ven agraviados con la práctica del acoso escolar y ciberbullying.

\section{Trump, el muro con México y la separación de hijos y padres}

\section{en la frontera}

El afán del presidente de los Estados Unidos por levantar un muro en la frontera con México (El País, 2018), para frenar las marchas de hispanos hacia el norte y detener a los inmigrantes que buscan una vida mejor, es una difícil decisión arraigada en la xenofobia, el racismo y la intransigencia, que mucho tienen que ver con Derechos Humanos como el art. 13: "Toda persona tiene derecho a circular libremente y a elegir su residencia en el territorio de un Estado", o el art. 3 a favor del derecho a la seguridad, vida y libertad de las personas.

El hecho de que se separen a hijos y padres en la frontera de México con Estados Unidos (El Español, 2018), es otro escándalo que hace pensar que algunos artículos de los Derechos de la Infancia son vulnerados, como por ejemplo el art. 10 "todos los niños y sus padres (...) tienen derecho a salir de cualquier país y entrar en el propio...", o el art. 5 sobre la obligación expresa del Estado para "respetar los derechos de los padres", o el art. 8, sobre la protección y la identidad del menor, o también el art. 11 relativo a la lucha contra los "traslados ilícitos y la retención ilícita de los niños en el extranjero". En cualquier caso, la "protección especial a los niños considerados refugiados o que lo soliciten", también es obligación del Estado (art. 22). Los valores que se ven arrinconados en ambos hechos tienen que ver con la estabilidad, la libertad, la familia, la seguridad física, la solidaridad, la humanidad, el desarrollo, etc.

\section{El complejo problema de Venezuela}

La crisis de Venezuela tiene muchas aristas (BBC, 2017), la mayoría de los venezolanos no pueden comprar comida, pues lo que ganan no les da para nada. El coste de los alimentos se ha disparado, igual que la devaluación de su moneda. Con el escaso sueldo apenas pueden cubrir 2,5\% de lo que requiere un hogar de cinco personas. La situación con los bancos se agrava. Tres millones y medios han salido de su país, 


\section{CIÊNCIAS HUMANAS}

buscando comida, trabajo y paz. Siendo un país inmensamente rico, están inmersos en el caos, el hambre, la violencia, el narcotráfico y la muerte. Los venezolanos necesitan buenos modelos que tomen sanas decisiones, que no se conviertan en escándalos éticos de abusos continuados. La reorganización democrática y social con el apoyo internacional y de organismos es un problema largo y complicado.

Todas estas situaciones que vive el pueblo venezolano afectan a Derechos Humanos como el art. 25 y 28 ya señalados donde "toda persona tiene derecho a un nivel de vida adecuado, a su familia, salud y bienestar, y en especial, a alimentación, vestido, asistencia médica y servicios sociales necesarios", y a que se establezca un orden social e internacional...".

Por su parte, los menores, en relación con los Derechos del Niño, "tienen derecho a disfrutar de la salud y del acceso a los servicios médicos y de rehabilitación (...), a los cuidados preventivos y disminución de la mortalidad infantil" (art. 24), buscando siempre la consideración del "interés superior del menor (art. 3), donde el Estado ha de cuidar y proteger al menor cuando los padres y madres, $\mathrm{u}$ otras personas responsables, no tengan capacidad para hacerlo". La humanidad, solidaridad, salud, familia, honradez, etc, son algunos de los valores que en estas situaciones se ven quebrantados.

\section{Los 264 millones de niños que no van al colegio}

Casi un tercio de los menores sin escolarizar viven en 35 países (Siria, Yemen, Sudan del Sur, Afganistán, Nigeria...) afectados por distintos conflictos políticos, religiosos, persecuciones, situación económica, cambio climático... que les llevan a situaciones de emergentes. Tan solo la mitad de los niños refugiados asisten a educación primaria y apenas un $25 \%$ a los primeros años de secundaria. Datos de Unicef nos indican que en todo el mundo hay 264 millones de menores sin escolarizar. De los cuales 75 millones están en los 35 países que viven situaciones de emergencia como las señaladas.

Esto es un escándalo ético global muy importante, pues la educación (arts. 26 y 28), o al trabajo y la libre elección de este (art. 23), o el mismo art. 29, donde el "Estado 


\section{CIÊNCIAS HUMANAS}

reconoce la educación como orientada a desarrollar la personalidad y las capacidades del niño y prepararlo para la vida adulta", son Derechos Humanos fundamentales vulnerados.

Desde el punto de vista de los menores, los arts. 28 y 29, hacen referencia al derecho a la educación y al reconocimiento del Estado por "la educación orientada a desarrollar la personalidad y las capacidades del niño y prepararlo para la vida adulta”. La educación, la libertad, la justicia, el trabajo, entre otros, son algunos de los valores que se ven agraviados por estas acciones.

\section{Escándalos éticos a nivel nacional}

En España contamos diariamente con muchos casos de escándalos éticos, por las malas decisiones tomadas individual o colectivamente. Aquí algunos ejemplos:

\section{Los bebés robados:}

Los bebes robados (Diario La Política, 2017) en nuestro país durante la postguerra de 1936 hasta los años 90, se convierte en un tema social con mucho eco, produciendo mucho dolor al conocer los orígenes y las consecuencias. Son víctimas de la época del franquismo que, tras la transición democrática, muchas familias y víctimas han sabido después de muchos años que, los hijos que creían muertos, fueron arrebatados y entregados a otras familias, quizás de mejor condición económica o social, pero sin justificación. Es muy noble querer ser madre y padre, pero no por esta decisión. Es injusto, egoísta, inmoral, ilegal e inhumano.

Se vulneran entre otros, el art. 1 de los Derechos Humanos: "todos nacen libres en iguales en dignidad y derechos" y el art. 6: "todo ser humano tiene derecho al reconocimiento de su personalidad jurídica".

En relación con los Derechos del Niño, es contrario al art. 3: "el Estado debe proteger y cuidar al niño" y al art. 36: "el niño tiene derecho a recibir protección ante cualquier forma de explotación". Los valores de justicia, familia y libertad se han mancillado. El incumplimiento de al menos estos Derechos y valores han producido un dolor irreparable. 


\section{CIÊNCIAS HUMANAS}

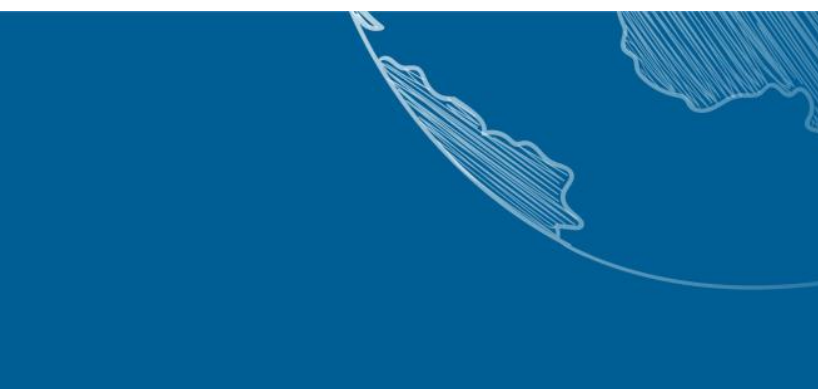

\section{Las niñas de Alcásser: Agresiones sexuales, torturas y}

\section{asesinatos}

Las agresiones sexuales a jóvenes adolescentes, es un suceso desgraciadamente frecuente, a pesar de la concienciación que tiene la sociedad y la formación y empoderamiento de las mujeres ante estas circunstancias. El conocido caso de las niñas de Alcásser en 1993 (La Vanguardia, (2018), supuso desconfianza y rabia. Fueron violadas, torturadas cruelmente y asesinadas. No hay preguntas ni respuesta para situaciones así. No hay pena suficiente para los agresores. El dolor de familiares, amigos y resto de la sociedad no tenía fin. Aún hoy se recuerda. ¿Qué puede pasar por la cabeza de los agresores para decidir y ejecutar esto? Sólo empatizando con las víctimas podríamos comenzar a suponer el dolor y el sufrimiento.

En estos hechos, hay muchos Derechos transgredidos, entre los fundamentales: "Todos nacen libres en igualdad de dignidad y derechos" (art. 1); "toda persona tiene derechos y libertades sin distinción alguna" (art. 2); "nada de torturas ni penas o tratos crueles, inhumanos o degradantes" (art. 5). Y sobre los Derechos del Niño, se vulneran entre otros, los artículos 3 y 37 respectivamente: "El Estado debe proteger y cuidar al niño" y "ningún niño será sometido a tratos crueles, inhumanos o degradantes". En estos casos se agravian valores como el respeto, la dignidad, la humanidad, etc.

\section{Los migrantes del 'Aquarius'}

Aquarius es el barco maldito que no encontraba puerto para desembarcar (Diario El Español, 2018). Ni Italia, ni Malta, los quería recibir. Eran 630 inmigrantes que navegaron a la deriva por el por el Mediterráneo en un barco que les recogió del mar, priorizando lo humano por encima de lo profesional. El puerto de Valencia finalmente les acogió. Al Aquarius, les han seguido el Dattilo y otros barcos contando con la colaboración de la Guardia Civil y ONGs. Aquí destacaba la ética y el buen hacer solidario de muchos, al menos en apariencia social. Pero lo que queremos destacar ahora 


\section{CIÊNCIAS HUMANAS}

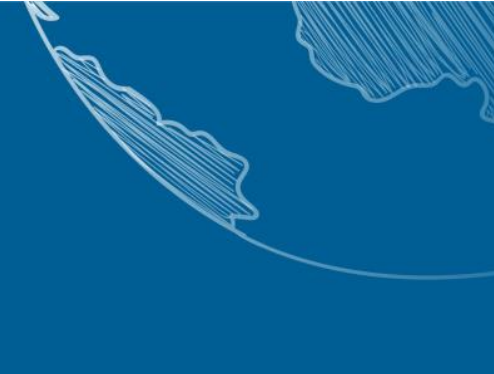

es el escándalo ético de los países y puertos que les han rechazado con las evidentes necesidades humanas que mostraban.

Esto ha ido contra Derecho Humanos como que "toda persona tiene derecho a una nacionalidad" (art. 15.1) y a que "toda persona pueda circular libremente y a elegir su residencia en el territorio de un país" (art. 13.1).

Desde el punto de vista de los Derechos del Niño, el art. 6: "todo niño tiene derecho a la vida y es obligación del Estado garantizar su supervivencia y desarrollo" y el art. 22: "se proporcionará protección especial a los niños considerados refugiados o que soliciten el estatuto de refugiado, y es obligación del Estado cooperar con los organismos competentes para garantizar dicha protección y asistencia”. La libertad, la salud, la paz serían algunos de los valores quebrantados.

\section{Las mujeres cobran menos por el mismo trabajo}

La brecha salarial se hace cada vez más grande: las mujeres ganan menos que los hombres (Diario El Mundo, 2018) por un mismo trabajo realizado, y en la jubilación son más pobres y vulnerables. Los datos del estudio "Brecha salarial y techo de cristal" presentado en febrero de 2018 con datos de la Agencia Tributaria, indican que ellas cobran 4.745 euros menos al año, lo que significa medio punto porcentual, siendo más las mujeres que los hombres las que no alcanzan los mil euros al mes.

Los Derechos fundamentales que aquí se ignoran tienen que ver con el art. 23.1: "Toda persona tiene derecho al trabajo, a la libre elección de su trabajo, a condiciones equitativas y satisfactorias de trabajo y a la protección contra el desempleo", y el art. 23.2: "toda persona tiene derecho sin discriminación alguna, a igual salario por trabajo igual".

Respecto de los Derechos del Niño, los artículos 3 y 32 ya expresados, sobre el interés superior del menor y la protección del Estado sobre el menor contra el desempeño de cualquier trabajo nocivo para su salud, educación o desarrollo", son los que destacaríamos. Los valores de igualdad, dignidad y justicia son, en este caso, los infringidos. 


\section{CIÊNCIAS HUMANAS}

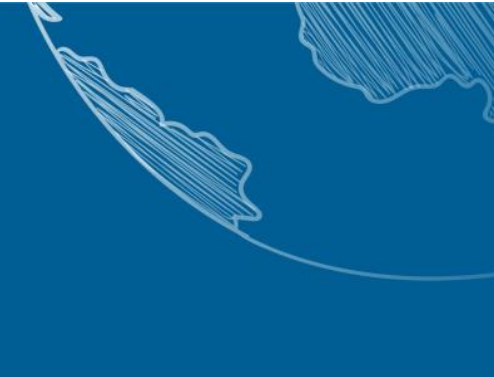

\section{Inmigrantes en centros de menores (Ceuta y Melilla, 2018):}

Los Mena o "menores extranjeros no acompañados" (El Faro de Ceuta, 2019) llevan años llegando de África a Ceuta y Melilla, pero en estos últimos años las cifras se han incrementado, colapsando los centros de menores de ambas ciudades. Según datos de Save the Children, en 2017 había 6.414 menores migrantes no acompañados tutelados, un 60,4\% más que en 2016. Estos niños y chicos llegan a estas ciudades escapando de la pobreza de sus lugares de origen, buscando un trabajo y un sitio donde vivir; muchos de ellos para reunirse con familiares que ya viven en Europa. Durante su largo viaje se ven expuestos a adversidades que les obliga a enfrentarse a la adversidad, perdiendo pronto parte de su infancia. Algunos de ellos, los documentados, son llevados a Ceuta y Melilla por sus propios padres y luego son abandonados allí a su suerte.

Como menores migrantes que son, todos tienen derecho a ser acogidos por un sistema que les dé protección, bienestar y los integre. Aunque en estas circunstancias, el sistema no siempre funciona como debiera. Muchos de ellos escapan de los centros de acogida y malviven en el puerto, esperando huir como polizones en las bodegas de algún ferry que los lleve hasta la península.

E1 Derecho a "circular libremente y a elegir su residencia y el derecho a salir de cualquier país" (art. 13), junto con el "derecho a un nivel de vida adecuado, salud y bienestar" (art. 25) sería Derechos Humanos especialmente afectados.

Respecto de los Derechos de la infancia, son especialmente trasgredidos el art. 20: "Es obligación del Estado proporcionar protección especial a los niños privados de su medio familiar y cuidados que sustituyan la atención familiar, incluida la colocación en un establecimiento apropiado" y el art. 10: "el derecho a salir de cualquier país y entrar con miras a la reunificación familiar”. El bienestar, la protección y la seguridad serían dos valores alejados de esta realidad. 


\section{CIÊNCIAS HUMANAS}

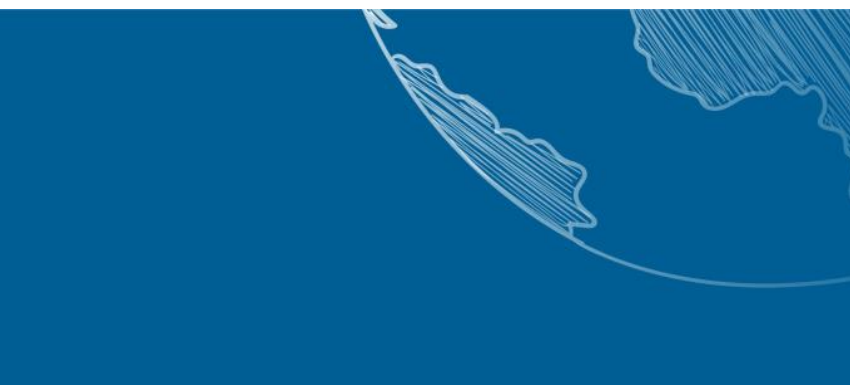

\section{CONCLUSIONES}

La relación entre planteamientos y criterios sobre la moral, la ética, los Derechos Humanos, los Derechos del Niño y los valores, resulta fundamental para entender cómo se explican cada término y como se interrelacionan. La justificación y articulación de estos, supone una base teórica de conocimiento necesario para todos, en especial para quienes realizan reflexión contante sobre procedimientos éticos y morales en determinadas actuaciones y las respuestas personales o institucionales, amparadas con la responsabilidad personal y la corresponsabilidad participativa sobre las mismas.

La filosofía moral puede proporcionar las herramientas que necesitamos para examinar y vivir una vida ética saludable. La metaética, la ética normativa y la ética aplicada, como ramas importantes de la filosofía moral, ayudan a realizar la reflexión necesaria a partir de la moralidad, la justicia, la verdad y las creencias, de lo correcto y lo incorrecto y de los temas de importancia moral, como las guerras, emprendiendo los desafíos morales necesarios en la actividad diaria.

La ética y la moral se pueden utilizar como términos asimilables e intercambiables, ya que buscan valores comunes importantes como el respeto, la honestidad, la responsabilidad, etc., y distinguen lo correcto de lo incorrecto, lo bueno de lo malo, desde los razonamientos e implicaciones personales e institucionales.

Los derechos se ven afectados positiva o negativamente por las decisiones individuales o participativas, a la luz de la reflexión ética, sabiendo que los derechos implican deberes y obligaciones propios de las personas y reclamados por estas en su ausencia.

Ética y derechos se relacionan a través de las normas y los estándares como indicadores que, al cumplirse, guian las acciones de los Estados y de quienes nos vemos inmersos en ellos. La Declaración Universal de los Derechos Humanos, con sus tres generaciones de Derechos Humanos: Los de la Declaración de 1798, los Derechos del siglo XX, que están en la Declaración de 1948 y los Derechos de la Tercera Generación, que contribuyen preocupaciones sociales de paz, desarrollo y medio ambiente, responden a los deberes que han de ser sumidos por todos. A estos sumamos los Derechos del Niño, 


\section{CIÊNCIAS HUMANAS}

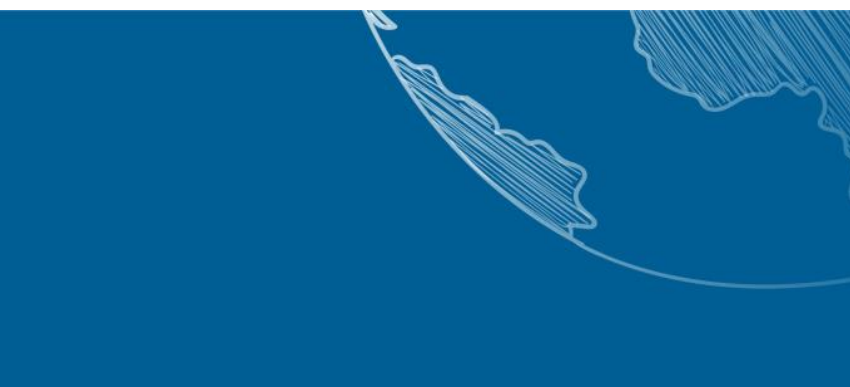

como expresión del respeto a los menores, en respaldo de su vida, desarrollo personal, bajo la protección del Estado, padres o tutores, que han de favorecer su educación y la consideración constante de su interés superior.

Los escándalos éticos, suponen un abuso de personas sin escrúpulos, que deciden sin considerar los derechos y valores asumidos por todos, buscando los favores personales o de sus organismos, en detrimento de las personas directamente relacionadas y de toda la comunidad, que vive y siente como propias, las alegrías y desdichas en la vida de los suyos. Por todo ello, se hace necesario una formación específica y continua de todos en materia de ética, moral, derechos y valores, en especial de aquellos que han de formar a otras personas, y de los que asumen una responsabilidad al frente de sectores sociales, siendo garantes de lo bueno o no que aporten a la vida cercana y global.

La vida y la libertad son derechos y valores esenciales para el desarrollo del ser humano. Como plantea la pirámide de necesidades de Maslow, estos valores se relacionan con las necesidades básicas en relación con un adecuado desarrollo integral de la persona. En el momento en el que no se respetan los Derechos y valores, se está negando la consecución de las necesidades básicas y, por tanto, la vida y libertad personal.

Los escándalos éticos nacionales e internacionales, suponen la concreción de hechos que existentes y que son analizados objetivamente, a la luz del marco teóricopráctico expuesto basado en la ética, la moral, los derechos y los valores. Son una llamada de atención constante para toda la ciudadanía y la aldea global, pues han de ser atendidos con la urgencia que demandan su atención y derechos por el hecho de ser personas en igualdad, reciprocidad, respeto y paz para todos.

Los niños y niñas representan la expresión de la vida del presente y del futuro. Los menores se empapan de los valores que aprenden en la familia, en la escuela y en la sociedad. Estos valores dependen del enfoque ético, moral y normativo que hayan aprendido y del ejemplo y modelo de vida, actitudes y valores que los adultos y la sociedad en general les ofrezcamos. La educación como derecho, valor, fin y principio es tan fundamental como necesaria para el desarrollo y madurez de los menores, para que 
sepan disfrutar de la niñez, se encaminen de la mejor manera hacia la vida adulta, productiva y profesional, y respondan con la ética necesaria a los problemas y decisiones que la vida les reserva.

\section{REFERENCIAS BIBLIOGRÁFICAS:}

ÁLVAREZ VÉLEZ, M.-I.-CALVO BLANCO, E. Derechos del niño. McGraw Hill: Madrid, 1998.

ARIÈS, Philippe. L'enfant et la vie familiale sous l'Ancient Régime, Plon, Paris. Después hizo una reedición en Du Seuil (Paris 1973). La traducción española es de Taurus (1987).

ARRATIA FIGUEROA, A. Ética, solidaridad y aprendizaje servicio en la educación superior. Acta bioethica, 14(1), 61-67. 2008.

ARTEAGABEITIA GONZÁLEZ, I. Los derechos del menor. Boletín Oficial del Estado. Madrid, 2007.

AUSTIN, DWYER, H. \& FREEBODY, P. Schooling the child, Routledge / Falme: Londres, 2003.

BAJO, F. \& BETRÁN, J.L. Breve historia de la infancia. Temas de Hoy. Madrid, 1998. BAÑÓN, A. J., GUILLÉN, M. \& RAMOS, N. La empresa ética y responsable.

Universia Business Review, 30, 32-43. 2011.

BBC. 6 preguntas para saber qué está pasando en Venezuela y qué salidas tiene la crisis. Recuperado de <https://www.bbc.com/mundo/noticias-america-latina-39710573> Acceso en 2017.

CONVENCIÓN SOBRE LOS DERECHOS DEL NIÑO. Convención sobre los derechos del niño de 20 de noviembre de 1989. Comité Español del UNICEF: Madrid, 1989.

CÓRDOBA, M. Comportamiento ético gerencial. Revista Icade. Revista de las

Facultades de Derecho y Ciencias Económicas y Empresariales. (64), 109-133. 2005.

DEL VAL, J. El desarrollo humano. Siglo XXI. Madrid, 6ª ed, 2004.

DIARIO LA POLÍTICA. (2007). Los bebés robados. Recuperado de < http://www.lapolitica.com/bebes-robados/ > Acceso en 2019. 
EL ESPAÑOL. Esto es lo que sabemos de los niños separados en la frontera de Estados Unidos con México. Recuperado de

$<$ https://cnnespanol.cnn.com/2018/06/26/ninos-separados-frontera-estados-unidos-

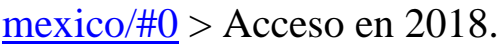

EL ESPAÑOL. Los migrantes del Aquarius, el barco maldito que nadie quería, desembarca en Valencia. Recuperado de

<https://www.elespanol.com/espana/20180617/atraca-valencia-dattilo-inmigrantesaquarius/315718543_0.html > Acceso en 2018.

EL FARO DE CEUTA. Menores extranjeros no acompañados (MENA). Recuperado de < https://elfarodeceuta.es/tag/mena/> Acceso en 2019.

EL MUNDO. La brecha salarial aumenta en España: Las mujeres cobran un $\mathbf{3 0 \%}$ menos y soportan más precariedad. Recuperado de

< https://www.elmundo.es/economia/macroeconomia/2018/02/12/5a8190e6e5fdeaa55d8b $\underline{4648 . h t m l}>$ Acceso en 2018.

EL PAÍS. ¿Por qué hay $\mathbf{2 6 4}$ millones de niños que no van al colegio? Recuperado de $<$ https://elpais.com/elpais/2018/04/23/planeta_futuro/1524501231_565813.html > Acceso en 2018.

EL PAÍS. Así es el muro de Trump. Recuperado de <https://elpais.com/tag/muro_estados_unidos_mexico/a > Acceso en 2018.

FUNDACIÓN ANAR Y MUTUA MADRILEÑA. III Estudio sobre acoso escolar y ciberbullying según los afectados. Recuperado de $<$ https://www.anar.org/iii-estudioacoso-escolar-y-ciberbullying-segun-los-afectados/ > Acceso en 2018.

FURNHAM, A. Psicología Organizacional: El comportamiento del individuo en las organizaciones. Oxford. 2001.

GIMENO SACRISTÁN, J. El alumno como invención. Morata: Madrid, 2003.

GONZÁLEZ-ALONSO, Fernando \& GUZÓN-NESTAR, José Luis. La educación en valores: Axiología, naturaleza y derecho educativo. Education in values: Axiology, nature and educational law. Revista Ciências Humanas. v. 18, nº 2[31], septiembre / diciembre, pp. 90-120. 2017.

HART-J. HIMES-G. LANSDOWN, Comentario y recomendaciones para las iniciativas de la UNICEF y Rädda Barnen relativas al derecho del niño a la participación, según lo estipulado por la Convención sobre los derechos del niño, en B. ABEGGLEN-R.

BENES, La participación e niños y adolescentes en el contexto de la Convención sobre

\begin{tabular}{l|l|l}
\hline Rev. Ciências Humanas & Frederico Westphalen, RS & Jan./abr. 2019
\end{tabular}

\begin{tabular}{l|l|l} 
Recebido em: 27/02/2019 & Aceito em: 26/04/2019 & Pg. 4-35
\end{tabular}


los derechos del niño: visiones y perspectivas UNICEF. Actas del Seminario, Bogotá: 78 de diciembre, p. 50. 1988.

IZQUIERDO, A. B. Dilemas éticos en trabajo social: el modelo de la ley social. Portularia: Revista de Trabajo Social, (9), 123-131. 2009.

KLIKSBERG, B. (2011). ¿Cómo enfrentar la pobreza y la desigualdad? Los escándalos éticos de nuestro tiempo. Suplemento especial de Página 12. Recuperado de <https://www.pagina12.com.ar/especiales/archivo/bernardo_kliksberg/1los_escandalos_eticos_de_nuestro_tiempo.pdf $>$ Acceso en 2019.

LA VANGUARDIA. Miguel Ricart, asesino de "Las niñas de Alcásser". Recuperado de $<$ https://www.lavanguardia.com/sucesos/20181109/452781438504/miguel-ricartninas-alcasser-crimen-cabeza-turco-antonio-angles-desaparecido-las-caras-del-mal.html > Acceso en 2018.

MANZINI, J.L. Declaración de Helsinki: Principios éticos para la investigación médica sobre sujetos humanos, Acta bioethica 6/2, 323-334. 2000.

MARTÍNEZ RODRÍGUEZ, J.B. Educación para la ciudadanía, Morata: Madrid, 2005, p. 50.

MASLOW, Abraham. Motivación y personalidad. Barcelona: Sagitario. 1954.

MONTUSCHI, L. Ética y razonamiento moral: Dilemas morales y comportamiento ético en las organizaciones (No. 219). Serie Documentos de Trabajo. 2002.

NACIONES UNIDAS, Los Derechos del Niño, Centro de Derechos Humanos, Ginebra, 1990.

ONU. Declaración Universal de los Derechos Humanos. (1948). Recuperado de < http://www.un.org/es/universal-declaration-human-rights/ > Acceso en 2018.

PAJA BURGOA, J.-A., La convención de los Derechos del niño, Tecnos: Madrid, 1998.

PECES BARBA, Gregorio. Historia de los derechos fundamentales, Dykinson: Madrid, 34-36. 2014.

ROMERO, G. E. Principios y valores éticos en las organizaciones bancarias respecto a la calidad del servicio y atención al cliente. Revista venezolana de gerencia, 11(36), 638655. 2006. 


\section{(1) URI|}

SORIANO DÍAZ, R. Historia temática de los derechos humanos, Mad: Madrid 2003, 45-53.

VVAA.: Educación plena en derechos humanos, Trotta: Madrid, 2014.

ZAROR SÁNCHEZ, C., \& VERGARA GONZÁLEZ, C. Ética en el currículo de las carreras de odontología. Acta bioethica, 14(2), 212-218. 2008. 